\title{
The Implementation of Assertive Training to Reduce Aggressive Behaviors of Students With Mild Intellectual Disability
}

\author{
Endang Pudjiasuti Sartinah* \\ Universitas Negeri Surabaya \\ Surabaya, Indonesia \\ endangsartinah@unesa.ac.id*
}

\author{
Rischa Hudzaimi Zulfah \\ Universitas Negeri Surabaya \\ Surabaya, Indonesia \\ rischa.hudzaimi@gmail.com
}

\author{
Siti Mahmudah \\ Universitas Negeri Surabaya \\ Surabaya, Indonesia \\ sitimahmudah@unesa.ac.id
}

\begin{abstract}
The purpose of this study is to describe the effect of assertive training to reduce aggressive behavior of students with mild intellectual disability of grade ten SMALB (Special Senior Public School) Sidoarjo. This study used a quantitative approach with type Single Subject Research (SSR), A-B-A design. The technique of collecting data used observation. The data analysis technique used was visual analysis in conditions and visual analysis between conditions for frequency and duration data, while quality data were analyzed using descriptive percentage techniques. The results showed that in the baseline phase (A1) the average aggressive behaviors of students during the $\mathbf{4 0}$ minutes is 35,5 seconds with an average frequency of 14.25 times with the quality of severe aggressive behaviors. In the Intervention phase $(B)$ the average aggressive behaviors carried out by students in 40 minutes was 9.2 seconds with an average frequency of 5.7 times with a mild quality of aggressive behaviors. In the baseline phase (A2) the average aggressive behavior carried out by students in 40 minutes was 15.5 seconds with an average frequency of 7.25 times with mild aggressive behavior. Thus, it can be concluded that during the intervention phase there was an effect of assertive training to reduce the aggressive behaviors of students with mild intellectual disability.
\end{abstract}

Keywords-aggressive behaviors, assertive training, children with mild intellectual disability

\section{INTRODUCTION}

Sometimes, during the process of educating a child, parents are often faced with various problems related to the development of their child's life. One of them is about the child's emotional development. Emotions are a person's tendency to act, a biological and psychological state that leads to a feeling or thought in the individual. So it is not surprising if someone's way of acting is strongly influenced by the presence of emotions [1].

Basically emotions have an important role to shape one's feelings and mind. In other words, the emotions contained within a person will be reflected through expressions and feelings. There are two dimensions to one's emotional experience, namely negative feelings and positive feelings. Positive feelings refer to emotions such as happiness, pleasure, attraction. While negative feelings refer to emotions, such as anger, guilt and sadness.
The development of one's emotions is determined by various factors that are internal and external. One of the determinants of a child's emotional development is maturity and learning factors [2]. Emotional maturity comes from a person's mental maturity to be able to recognize, accept, and process his/her emotions influenced by chronological age. In other words, when a person grows older he/she will increase his readiness and ability to learn and recognize the various emotions around him/her.

The process of emotional development will generally be hampered in children with intellectual disability. Children with intellectual disability are the children who have intellectual abilities below the average [3]. Intellectual disability refers to the general intellectual ability that is significantly below the average accompanied by adaptive behaviour difficulties or adjustments that take place during the developmental period. In addition to deficiencies in social adjustment, children with intellectual disability also experience obstacles in various developments in their lives, one of which is obstacles in behavioural and emotional development.

Intellectual barriers experienced by children with intellectual disability will affect the development of emotions. This happens because intellectual ability allows a child to recognize new knowledge that was previously not understood, and focus emotional tension on a particular object. So it is not surprising if in their daily lives, children with intellectual disabilities tend to show unstable and un directed emotions.

There are some common characteristics that can be found in mentally retarded children include: Children with intellectual disabilities have abstract learning capacities such as learning and counting, writing and reading are limited. Learning skills tend to be without understanding or tend to learn by parrot. Children with intellectual disabilities experience barriers to behaviour. Barriers to behaviour can be seen from his personal balance that is less constant or unstable, sometimes unstable and looks chaotic. This condition can be seen from the appearance of his daily behaviour, for example: staying silent for hours, or it can also behave destructively and aggressively, such as irritability and irritability, and likes to disturb other people around him. in addition to showing the aggressive behaviour of mentally retarded children also shows a disturbance in 
adaptive behaviour. In addition to the limitations of intelligence, mentally retarded children also have difficulties in taking care of themselves in the community, therefore they need help. Not able to shoulder social responsibility wisely so that it needs supervision and guidance. They are also easily influenced and tend to do things without thinking about it.

Children with intellectual disabilities also have limitations in language acquisition. They are not experiencing articulation damage but management (vocabulary) that is not functioning as it should. Furthermore, mental retardation children need more time to complete the reaction in a situation that is new to them and cannot deal with an activity or task for a long time. children with intellectual disabilities are not able to consider something and can not imagine in advance the consequences of an action. Retarded children may not trust their own solutions to problems and seek guidance to act in their immediate environment.

Unstable and undirected emotions are caused by intellectual barriers that indirectly affect a child's ability to manage information from the outside which will lead to presuppositional errors so that children with intellectual disability become difficult to sort out, and manage their own emotions. This is supported by research in accordance with the field, which proves that children with intellectual disability experience a decreased ability to identify emotions in themselves and others, have relative control over peers who are mentally suitable for those who have no disabilities, $[4,5]$.

Difficulties in managing emotions will trigger behavioural problems in children with intellectual disability. One such behaviour problem is aggressive behaviour. Aggressive behaviour is violent behaviour and willpower [6]. Aggressive behaviour is a negative behaviour that is often shown through anger towards something, for example, attacking other people if their wishes or desires are not fulfilled.

Aggressive behaviour is negative behaviour that arises as a result of stimulation of events or situations that are considered unpleasant. forms of aggressive behaviour can be clarified including: 1) physical aggressive, 2) verbal aggressive, 3) aggressive anger, 4) aggressive in the form of hostility. Aggressive behaviour that occurs in individuals can be caused by a variety of causes behind the aggressive behaviour is carried out. The cause of aggressive behaviour can occur due to internal and external factors of the individual. Aggressive behaviour which is a form of negative emotions, does not necessarily just happen but can be triggered by several processes that are mutually sustainable.

Children who tend to behave aggressively or are less able to express their anger in forms that are acceptable to the environment will have a negative impact. These impacts can affect both himself and others. The impact on himself is to be shunned by his friends and have a bad self-concept. Children will be labelled as naughty children so that makes it feel less safe and less happy. Impact on the environment, which can cause fear for other children and will create unhealthy social relationships with peers. In addition, it can disturb the peace of the environment because usually children who behave aggressively have a tendency to damage something around them.

To reduce aggressive behaviour of children there are a number of things that can be done including: keep children away from things that can lead to aggression such as television, video games that contain elements of violence, give children teaching to behave well and politely, give children examples to behave assertively instead aggressive, help children to learn to solve problems that can cause aggression in him, give consequences to children when behaving aggressively, Avoid defending when children do wrong.

Based on the observation in one Special Senior High School, children with intellectual disability were found with aggressive behaviour both verbally and non-verbally. This condition is in line with the opinion of Asri [7], who states that most children with intellectual disability have an aggressive nature both verbally and physically. Aggressive levels proved in children with intellectual disability based on prevalence surveys showed aggressive rates of $35 \%$ to $38.2 \%$ in institutions, $9.7 \%$ in families and $17 \%$ in the community $[8,9]$.

This kind of situation makes children with intellectual disability often shunned and become ostracized by others around them. As a result, they are less able to be publicized in social activities, even often get strong resistance to being able to interact with the community because they are considered disturbing and dangerous in social life.

This situation is exacerbated because on average children with intellectual disability are less likely to handle aggressive behaviour appropriately in school. Because in general, the average school only focuses on academic development, talents, interests and skills of students. Even if there is only the formation of character and morale of students, while for intervention and intervention programs regarding behaviour, especially aggressive behaviour in students is still lacking.

Therefore, children with intellectual disability that require special handling and guidance to develop their emotional development. This particular guidance is needed especially for mild children with intellectual disability who are still able to interact socially in their environment, so that they can optimally blend and be accepted by their environment.

Indeed, to solve these problems, children with mild intellectual disability need proper handling through a behaviour modification program or behaviour change [10]. defines behaviour modification as an attempt to change a person's behaviour and emotions with a series of procedures that are useful based on the law and techniques of the learning process theory.

One behaviour modification technique is the assertive technique training or assertiveness training. Assertive training is a behaviour change technique whose main purpose is to guide, train and encourage someone to be able to behave assertively in certain circumstances [11].

In this assertive training children with mild intellectual disability will be trained to be able to recognize their feelings, both positive feelings and negative feelings. Then 
trained to manage emotions, learn situations that can lead to conflict, motivate themselves and develop relationships between humans by understanding the rights of others wisely.

Assertive training is a structural intervention that is used for improving social relations, therapy for anxiety disorders, and phobias in children, adolescents and adults. This training uses a multi-content method that includes guidance, role playing, feedback, modelling, training and a review of trained behaviour [12]. With assertive training, children with mild intellectual disability will be able to manage emotions, distinguish good and bad behaviour (assertive or aggressive) so that they can master their own behaviour in problematic conditions in order to increase the effectiveness of their social life, so that aggressive behaviour can be reduced and controlled.

Assertive training is used to train someone in expressing feelings while maintaining and paying attention to the rights and feelings of others. The main aim of this technique is to help individuals control themselves in various problematic situations by fighting the anxiety faced by individuals because of the perceived unfair treatment of the environment. Assertive training uses role playing Through playing the role of individuals will be taught to behave decisively while paying attention to the feelings and rights of others which will then be applied in real life. Role playing techniques function to express various kinds of oppressive feelings (negative feelings) through an atmosphere that is conditioned in such a way. So that someone can freely express himself through certain roles.

The research aimed to shortly describe whether there is influence of Assertive training to reduce the aggressive behaviour of one student with mild intellectual disability in grade 10 of special senior high school in Indonesia.

\section{METHOD}

The method used in this study was an experimental method with a single research subject. This method was used to see a change that appears as carefully as possible, so that a cause-and-effect relationship can be identified. Single subject research was a research which carried out with the aim to determine the magnitude of the influence of the treatment given repeatedly in a certain time. Referring to experiments with a single subject, the research design used was the ABA design. The ABA design has three phases, namely A-1 (Baseline 1), B (Intervention) and A-2 (Baseline). ABA design aims to determine the effect of the treatment given to the variables given to the subject. In addition, in the SSR study, ABA design aims to obtain data before the subjects get intervention or treatment, when getting an intervention and after getting treatment, then see whether there is a change after the influence given to the subject.

In the design of a single subject the measurement of the dependent variable or target behavior is carried out repeatedly with a certain time period such as per week, per day, or hourly. Comparisons are not made between individuals or groups but are carried out on the same subject under different conditions. The conditions referred to here are the Baseline conditions and the conditions of the experiment (treatment). Baseline is a condition where measurement of target behavior is done in a natural state before being given an intervention or treatment. While the experimental conditions are conditions where an intervention has been given and target behavior is measured under certain conditions.

In this research, assertive training is a procedure for behavior change that focuses on individuals who have difficulty in expressing their feelings or are often wrong in expressing their feelings. This training uses a multi-content method that includes guidance, role playing, feedback, modeling, training and a review of trained behavior. The steps in assertive training techniques are:

1. The first session, the researcher conveys the goal of therapy; help the subject to recognize their behavior (whether passive, aggressive or assertive); and provide knowledge about the characteristics of passive, aggressive and assertive behavior.

2. The second session, setting targets for behavior to be achieved, identifying situations that could lead to conflict and teaching the use of the word "I" in expressing opinions.

3. The third session, demonstrating how to communicate and behave assertively includes eye contact, body posture, body movements, facial expressions, voice and speech content using video recordings from a model.

4. The fourth session, playing roles together with peers to see how far the subject is able to master the assertive behavior that has been learned. Next, giving the task to apply assertive behavior to real situations outside the therapy room then the subject is asked to report what he has done to the practitioner.

5. The fifth session, giving feedback and evaluating what efforts can be learned, asking again how to show facial expressions, words and disagreement behavior.

6. The sixth session, provides provisions on how to express and express assertive behaviors (rejection, requests and praise), and provide reinforcement in the form of motivation so that the subject is able to express assertive behavior so as to reduce the pressure caused by conflicts with peers.

The subject in this study was one male student with mild intellectual disability of grade ten, and aged 16 years named BSW. He performs aggressive behavior in frequently in school. Data were collected through observation. Data analysis method used the simple statistic descriptive. According to Sugiyono [13] statistics descriptive statistics used for analyze data with way describe it or describe the data that has been collected as is existence without intend make conclusions apply for general or generalization. Data on the form of frequency and duration were written in graph, then analyzed use visual graphic techniques (Visual Analysis of Data Graphs). Data in the A1 and A2 baseline phases were analyzed using analysis stability while data phase intervention (B) were analyzed based on its tendency.

The research data will be written in a graph, then analyzed using graph visual techniques (Visual Analysis of 
Graph Data). Visual graph analysis technique (Visual Analysis of Graph Data) consists of analysis in conditions and analysis between conditions. Visual analysis used in the analysis of conditions is to analyze changes in data in one condition such as baseline conditions or intervention conditions.

Research data in this study are presented in graphs. In this study, graphs are used to show data changes for each session and to show the average score of data in the baseline and intervention phases. In addition, data analysis activities in research with this single subject have several important components analyzed such as (1) data stability, (2) data tendency, (3) level of data change, (4) the average for each condition, and (5) overlapping data.

1. Analysis Under Conditions

Analysis in conditions is an analysis of changes in data in a condition such as baselines and interventions.

The components analyzed are:

\section{a.Length conditions}

Data length is the amount of data in the condition. For the length of the baseline conditions in general, three or five data points can be used. Nevertheless, the consideration is not the number of points but the stability

b.Estimation of direction trends

Estimation of direction trends is used to analyze data or target behavior during the intervention phase. The direction tendency on a graph is important to provide a picture of the behavior of the subject being studied. By using a combination of levels and trends, researchers can reliably determine the effect of controlled conditions (interventions). Trend graph direction shows the change in each data path (trace) from session to session.

c.Stability level

The level of stability shows the level of homogeneity of data in a condition. Intervention can be given if data stability is obtained at the baseline phase both at baseline A1 and baseline A2 .

2. Inter-Condition Analysis

Analysis between conditions related to the main components:

a. Variable changed

In analyzing data between conditions, the dependent variable or target behavior is focused on one behavior. this means that the analysis is emphasized in the effect or effect of the intervention on the target behavior.

b. Change in direction and effect

The direction graph between baseline and intervention conditions shows the meaning of changes in target behavior caused by the intervention.

c. Change in stability

Data reliability shows the stability level of change from a series of data. Data is said to be stable if the data shows the direction consistently.

d. Data level changes
Changes in data levels indicate how much data has changed, for example at baseline or intervention conditions

e. Overlap data

Data overlapping between the two conditions is the same data occurrence in both conditions.

In this study the results of research on frequency data and duration data will be analyzed with simple descriptive statistics by providing a table and line graph containing measurement results data at baseline 1 , intervention 1 , and baseline 2. Data changes in each condition at baseline 1, intervention 1, and baseline 2 which is then further analyzed using analysis under conditions. Each component of visual analysis in the condition is then included in the summary table of the results of visual analysis in the condition. The final step is to draw conclusions by comparing measurement data for each baseline 1, intervention 1, baseline 2 and intervention 2 conditions.

Whereas the quality data will be analyzed in percentage using a descriptive analysis technique percentage. Descriptive data analysis of this percentage is used to determine the categories of the quality of aggressive behavior. The target behavior in this study is inappropriate speaking behavior which is divided into 4 items of coverage, namely: (1) speaking dirty/disrespectfully, (2) speaking with words that ridicule/demean others, (3) students argue disrespectfully, (4) Students speak in neutral but use high notes.

\section{RESULT AND DISCUSSION}

Result

Observation of the aggressive behavior of one student in this study was carried out for 14 sessions which were divided into 3 phases. Data collection on the aggressive behavior of students is carried out in three aspects, namely, frequency, duration and quality. The first phase is the baseline (A1) phase which is carried out for 4 sessions in which observation of aggressive behavior was carried out in a situation where students have not been given any treatment.

The next phase is the intervention phase (B) which was carried out in 6 sessions or meetings. Observations in this condition were during the intervention or during intervention. Interventions in this study were conducted in six sessions in conformity with the assertive training procedure. In the first session student was guided to be able to recognize their own behavior, distinguish good and bad behavior. Then in the second phase student was guided to find solutions when situations that lead to conflict or aggressive behavior come. In the third session student was guided to be able to behave and communicate assertively through eye contact, conversation style, tone volume, etc. Then in the fourth session student was guided to recognize the types of assertive behavior (rejection, requests and praise). In the fifth session, student was guided to play a role with peers to practice the material that has been learned, afterwards student was guided to do real practice applying assertive behavior. In the last session feedback, evaluation, and motivation were held on what students had learned.

The last phase was the baseline phase (A2) which was carried out in 4 sessions. Observation of aggressive behavior carried out on subjects in normal conditions as a way to see the impact of the intervention that has been given. 
After the data were analyzed, in terms of both the frequency, duration and quality of the results showed that in the baseline phase (A1) the aggressive behavior of students was rated high, then decreased in the intervention phase (B), and slightly increased again in the baseline phase (A2). Decrease in behavior occurs in the intervention phase, where the frequency, duration and quality have decreased significantly from the baseline phase (A1) to the intervention phase. This proves that during the intervention, assertive training provides a good influence on student behavior.

The decrease in behavior that is not significant in the baseline phase (A2) is possible because of several reasons. Firstly, data collection in the intervention phase was done in a special therapy room individually, so students can be easily conditioned. Whereas in the baseline phase (A2), students are left without any treatment or under normal conditions. This proves that the decline in aggressive behavior only occurs significantly during intervention. In the intervention phase the student is placed in controlled conditions so that his behavior can be controlled as well. While at the baseline (A2) students' aggressive behavior was not controlled or given reinforcement so that allows students to behave aggressively again. lastly, based on observations during the baseline (A1) phase, the intervention phase and the baseline phase (A2), the student environment still cannot support students to behave assertively, and often still supports students to behave aggressively.

Apart from data on frequency, duration and quality. a decrease in aggressive behavior in students is characterized by an increase in student assertive behavior. Increasing assertive behavior of students during the intervention is characterized by an attitude that begins to be able to respect others such as saying thank you when receiving assistance or something, apologizing if you make a mistake or reject something and say a word of help when asking for help from others. Students are able to maintain eye contact while talking, speak in a firm sentence. But these changes have not happened consistently because students still often speak in high tones and volumes.

\section{Discussion}

The results of the study of BSW, a student with mild intellectual disability who experience intellectual and emotional obstacles. Intellectual barriers are characterized by delays in academic abilities, especially basic academic such as reading, writing, and math. Emotional barriers experienced by BSW are characterized by unstable emotions and cannot control their behavior. This is in line with research in accordance with their fields, which states that children with intellectual disabilities experience a decrease in their ability to identify emotions in themselves and others, have relative control over peers who are mentally ill who have no disabilities $[4,5]$.

Interventions in this study used assertive techniques training which is one technique in behavior modification. According to Panggabean [15] behavior modification is the application of shaping or gradual behavior formation, the use of positive reinforcement and extinction or deletion. Shaping was given an intervention using assertive training is in the form of self-training in the formation of assertive behavior. while the reinforcement is given through motivation, praise and the delivery of the consequences of aggressive behavior. Moreover, according to Gunarsa and Praktis [16] assertive behavior that reflects the attitude of honesty, openness in thoughts and feelings that can show through social conformity of the ability to adapt itself or conform to other people.

Moreover, Sigmund Freud [17] in his psychoanalytic theory assume that aggression carried out by someone is due to an impulse. Encouragement can come from inside and outside the individual. Encouragement from outside can come from the student environment. Such as interference from other students that make these students motivated to behave aggressively or the existence of an aggressive model in the student environment that makes students mimic the behavior. Therefore, as long as the environment still has great potential to encourage students to behave aggressively, the tendency of students to behave aggressively is still possible to continue.

\section{CONCLUSION}

Based on data analysis and discussion, it can be concluded that there is a significant effect from assertive training for reduce the aggressive behaviors of student with mild intellectual disability on the intervention phase. However, this condition is not happening in the baseline either before intervention or after intervention.

\section{REFERENCES}

[1] D. Goleman, Kecerdasan emosional. Gramedia Pustaka Utama, 2000.

[2] E. B. Hurlock, Perkembangan anak. Erlangga, 1978.

[3] S. Somantri, "Psikologi anak luar biasa," Bandung: Refika Aditama, 2006.

[4] R. P. Hobson, J. Ouston, and A. Lee, "Naming emotion in faces and voices: Abilities and disabilities in autism and mental retardation," Br. J. Dev. Psychol., vol. 7, no. 3, pp. 237-250, 1989.

[5] C. Mcalpine, N. N. Singh, K. A. Kendall, and C. R. Ellis, "Recognition of facial expressions of emotion by persons with mental retardation: A matched comparison study," Behav. Modif., vol. 16 , no. 4 , pp. $543-558,1992$.

[6] J. Kaufman and D. Cicchetti, "Effects of maltreatment on school-age children's socioemotional development: Assessments in a day-camp setting.," Dev. Psychol., vol. 25, no. 4, p. 516, 1989.

[7] P. Asri, "Anak Tunagrahita," 2007.

[8] R. W. Novaco and J. L. Taylor, "Assessment of anger and aggression in male offenders with developmental disabilities.," Psychol. Assess., vol. 16, no. 1, p. 42, 2004.

[9] M. J. Taylor, "Non-spatial attentional effects on P1," Clin. Neurophysiol., vol. 113, no. 12, pp. 1903-1908, 2002.

[10] H. J. Eysenck, Manual of the Maudsley personality inventory. University of London Press, 1959.

[11] P. Edi, "Modifikasi Perilaku (Alternatif Penanganan Anak Berkebutuhan Khusus)." Yogyakarta: Pustaka Pelajar Offset, 2012.

[12] P. J. McCartan and O. D. W. Hargie, "Assertiveness and caring: are they compatible?," J. Clin. Nurs., vol. 13, no. 6, pp. 707-713, 2004.

[13] Sugiyono, Metode Penelitian Kuantitatif, Kualitatif, dan Kombinasi (Mixed Methods). Bandung: Alfabeta, 2014.

[15] Sunardi, "Modifikasi Perilaku," 2010. .

[16] S. D. Gunarsa and P. Praktis, "Anak, remaja dan keluarga," Jakarta: Gunung Mulia, 2001.

[17] R. L. Atkinson, R. C. Atkinson, E. E. Smith, and D. J. Bem, "Pengantar Psikologi Edisi Kesebelas Jilid 2," Jakarta: Penerbit Interaksara, 1994. 